\title{
De la ficción bélica a la distinción como destino: lo Real de la antifilosofía entre Jacques Lacan y Alain Badiou.
}

\author{
From the war fiction to the distinction as destiny: the Real of the \\ antiphilosophy between Jacques Lacan and Alain Badiou.
}

Esta obra está bajo una Licencia Creative Commons Atribución 4.0 Internacional. DOI: $10.32870 /$ sincronia.axxii.n74.8b18

\author{
Kaira Vanessa Gámez \\ Universidad Católica Andrés Bello \\ kvgamez.m@gmail.com \\ (VENEZUELA)
}

Recibido: 29/03/2018

Revisado: $23 / 04 / 2018$

Aprobado: $12 / 06 / 2018$

\begin{abstract}
RESUMEN
En un punto avanzado de su enseñanza, Jacques Lacan resolvió calificarse a sí mismo como un "antifilósofo"; empleo enigmático de una palabra que, con razón o sin ella, despertaría la suspicacia de los filósofos. Alain Badiou, preocupado por los embates que la filosofía sufrió durante el siglo XX, advirtió en esta declaración lacaniana y, por ende, en el psicoanálisis mismo, la presencia de una amenaza para la filosofía que vaticinaba un litigio insalvable entre ambos campos. Partiendo del contraste entre sus respectivas nociones de lo real, se planteó como objetivo distinguir la concepción badiousiana de la antifilosofía del sentido que pudo haber tomado este significante al interior de la enseñanza lacaniana. Nuestra exploración no sólo puso de manifiesto que allí donde Badiou transitó de lo real como causa a lo real como consistencia, salvaguardó precisamente lo que exceptúa su filiación lacaniana, sino que el real lacaniano no es esa mostración eidética que el filósofo colige del acto matemático. En esa medida, y tras recurrir a la sofística gorgiana para iluminar este asunto, concluimos que es precisamente lo real lo que impide que aquella autoproclamación lacaniana pueda ser tomada como un estamento filosófico.
\end{abstract}

Palabras clave: Antifilosofía. Real. Lacan. Badiou. Psicoanálisis.

ABSTRACT 
At an advanced point in his teaching, Jacques Lacan decided to call himself an "anti-philosopher"; the enigmatic use of a word that, rightly or wrongly, would awaken the suspicion of philosophers. Alain Badiou, concerned about the attacks that philosophy suffered during the twentieth century, warned in this Lacanian statement and, therefore, in psychoanalysis itself, the presence of a threat to philosophy that predicted an insurmountable litigation between both fields. Starting from the contrast between their respective notions of the real, the objective was to distinguish the Badiousian conception of the antifilosophy from the sense that this signifier could have taken within the Lacanian teaching. Our exploration not only showed that where Badiou transited from the real as a cause to the real as a consistency, he safeguarded precisely what his Lacanian filiation excepted, but that the Lacanian real is not that eidetic show that the philosopher collects from the mathematical act. To that extent, and after resorting to the Gorgian sophistry to illuminate this matter, we conclude that it is precisely the real that prevents that Lacanian self-proclamation from being taken as a philosophical establishment.

Keywords: Antiphilosophy. Real. Lacan. Badiou. Psychoanalysis.

\section{Introducción}

Desearía, en esta segunda mañana de nuestro coloquio, tensar un poco la situación. Mostrar la gravedad y la complejidad de lo que se pone en juego. Lacan no es un filósofo, y no hay, no podría haber, filosofía de Lacan. Lacan sostiene con firmeza que su pensamiento procede esencialmente de su experiencia clínica. Esta experiencia como tal, es radicalmente, externa y ajena a la filosofía. Lacan debe ser recibido como un analista. Quizá fue durante una época el analista. Quizá, aunque muerto, aún sigue siendo el analista. [...] Lacan desde luego analizó, leyó, comentó a grandes filósofos. A decir verdad principalmente a siete [...] Pero finalmente colocó su empresa bajo la explícita bandera de la antifilosofía. Esta palabra es esencial. Lacan es un antifilósofo. ¿Vamos a admitir sin examen la reintegración entre nosotros -nosotros Colegio de Filosofía, Colegio de los Filósofos- a un antifilósofo declarado? ¿No es un juicio sobre nuestra propia derrota filosófica el reunirnos, el reunirse bajo el emblema sarcástico de la antifilosofía? Ahí radica la única pregunta que vale (Badiou, 2011, p. 127)

En el año 1990, el Colegio Internacional de Filosofía juzgó preciso abrir en su seno un inédito y sintomático espacio para la consideración formal del pensamiento de una figura que causó un 
verdadero cisma en la intelectualidad francesa contemporánea. Organizar un coloquio filosófico en torno al pensamiento de Jacques Lacan era el objetivo, pero hacerlo bajo la decisiva premisa de que "una doble relación con la filosofía marca profundamente su pensamiento" (Biblioteca del Colegio Internacional de Filosofía, 2011, p. 9), emergía como todo un acontecimiento que no sólo aceptaba una "influencia de esta manera de pensar, a partir de Freud, sobre la filosofía contemporánea" ( $p$. 9), sino que reconocía abiertamente "la participación del pensamiento lacaniano en los principales desafíos contemporáneos" (p. 9). Como señaló el comité organizador en su momento, se trataba de reabrir la cuestión de lo filosófico y lo psicoanalítico a partir del trabajo de Lacan, siendo precisamente a ello a lo que nos invitan las desafiantes líneas con las que Alain Badiou se presentó a tal evento.

Desde el Pequeño panteón portátil de este provocador filósofo, un par de voces esenciales y disímiles emergen como las responsables históricas de su inspiración. Quien inaugura el siglo de su memoria filosófica es, paradójicamente, psicoanalista. Un psicoanalista al que se refiere como un autor de referencia básica y como el analista de todos los tiempos (Badiou, 1990). Pocas plazas más adelante aparece Louis Althusser -quien antaño acogiera a Lacan en su propio pensamiento y en su escuela- ocupando una posición de honor. En su mausoleo reza la frase "verdadero maestro al que se le debe lo esencial" de una convicción: "la de la existencia insoslayable de la filosofía" (Badiou, 2003b, p. 44):

[...] en estos años de 1960, tan marcados de antifilosofía, tan abiertos a los temas conjuntos del nihilismo planetario y del reino de las ciencias humanas, Althusser fue casi el único en sostener un enunciado para mí todavía hoy crucial y disputado: hay filosofía bajo una forma racional. En este sentido fue, contrariamente a Lacan, a Foucault, o a Derrida, todos ellos antifilósofos, fue, sí, el filósofo. Y no solamente mantuvo que había filosofía, sino que enunció que la habría siempre. Sostuvo, en el fondo, la philosophia perennis" (Badiou, 2003b, p. 45). 
Igualmente esenciales, el 'filósofo' y 'el antifilósofo' se encuentran en su conmemoración. Hoy en día no es un secreto que con Alain Badiou la filosofía ha asistido a un vuelco radical que responde a la llegada de ese aliento de la postmodernidad que, a su juicio, dejó en ruinas el campo filosófico del siglo pasado. Preocupado por el "pathos del final de la filosofía", Badiou cerró el siglo XX instando a combatir toda tradición intelectual que declarara muerto el amor a la sabiduría. En efecto, su programa filosófico se halla definido por un objetivo fundamental: la rehabilitación de la filosofía a través de un replanteamiento de su lugar, de su función, y de sus condiciones de posibilidad (Dechen, 2013). Pero tal precepto de un retorno a lo filosófico no surgió aislado.

A partir de la década de 1980, cuando Badiou se entregó al diseño de un programa metaontológico orientado recuperar a la viabilidad del pensamiento filosófico, el interés por relegitimar lo que a todas luces parecía acabado precipitó un acucioso retorno de su parte a la decisión platónica de desterrar a los sofistas y a los poetas de su República. Y es que la filosofía que él buscaba restituir no había existido siempre, afirmó Badiou.

Ese momento fundador del pensamiento badiousiano se apuntaló en la afirmación de que fue el "gesto platónico" lo que le dio origen a esa disposición intelectual que en todo momento histórico enuncia el hay de las verdades (Badiou, 2013, p. 7). Al disponer 'la Verdad' como categoría operatoria frente al sino de los sofistas y los poetas, Platón sostuvo, según Badiou, un camino inmortal que es el único donde la filosofía puede siempre reencontrarse. Bajo esa luz, su empresa contemporánea no aspiraba a ser más que una continuación de dicho movimiento, lo cual llevó a Badiou a definir la filosofía como un acto, y no como cualquier acto, sino como ese que circunscribe el propio campo filosófico a partir de sus relaciones externas e internas (Tho, 2015).

Al declarar de manera inequívoca su identificación con el padre del idealismo, Badiou anunció un retorno al "gesto platónico" con el que aseguró que su acto filosófico, tanto como el platónico, consiste esencialmente en una tarea de confrontación: “El joven Platón comprendió que era preciso, a la vez, hacer caso omiso de los enredos sutiles de la sofística, e instruirse en ellos sobre la esencia de las cuestiones de su tiempo. Lo mismo aplica para nosotros" (Badiou, 1990, p. 
70). Badiou interpreta el talante mismo de la filosofía a partir de la determinación platónica de mantener a los cómplices de la sofística al exterior del proyecto filosófico (p. 69), de donde desprende la conclusión de que la filosofía es, ante todo, reafirmación de su posibilidad sistemática; tarea que no puede realizar sin trazar una línea de demarcación entre sí misma y aquello que sin ser filosofía, se le parece (Bosteels, 2008, p. 155). La filosofía estará, pues, truncada, siempre y cuando sus ejecutores no actúen la ficción bélica de su oposición frente al sofista.

Al instituir su posición frente a la del "adversario inmemorial del filósofo", Badiou no sólo polarizó todo el proceso filosófico en virtud de la verdad, sino que elevó la oposición sofista/filósofo a un estatuto primordial, disponiéndola como la duplicidad primera que funda la filosofía (Badiou, 2013, p. 9). Desde luego, la ética entera de la filosofía comenzó a jugarse para él en una constante retención respecto de su doble sofístico, lo cual signó en su horizonte una confrontación impostergable con 'la Gran Sofística Moderna' en cuyo seno ubicó a una serie de contra-figuras filosóficas a las que atribuyó como estrategia idiomática el "ahorrar toda aserción positiva referente a las verdades" (Badiou, 2013, p. 9). Fue entonces cuando Lacan -junto a Nietzsche y a Wittgenstein- comenzó a ocupar una posición de referencia formal en el pensamiento badiousiano.

Siguiendo a Tho (2015), no es sino en ese escenario de confrontación donde la emergencia del concepto de antifilosofía se volvió significativa para Badiou. Aunado a ello, Lacan representaba para él la referencia más íntima e inmediata del antifilósofo, siendo a partir del elusivo uso que el psicoanalista le dio a este término que Badiou comenzó a preguntarse a sí mismo qué sentido podría tener esa palabra que, eventualmente, le ayudaría a pensar la filosofía dialécticamente.

Cuando casi hubo completado la obra de su vida, el maestro francés del psicoanálisis revivió ese antiguo vocablo que nunca antes había proferido y que sólo volvería a escuchársele una vez más. La palabra 'antifilosofía' -envuelta en el misterio de lo jamás desarrollado- fue pronunciada por Lacan una vez en el Vincennes de 1975 y luego, cinco años más tarde, como parte de una suerte de testamento que dejó en el acto de disolución de la Escuela Freudiana de París. 
La dificultad implicada en ese uso del término reside, por supuesto, en su carácter puntual, aislado y consecuentemente hermético. Sin embargo, para un filósofo como Badiou, tan concernido por la restitución de las condiciones de posibilidad de la filosofía, no es de sorprender que tales alusiones, aunque escasas, resultaran potencialmente amenazantes. Preocupado por el derrotismo filosófico del mundo contemporáneo, nuestro autor vio en el hápax legómenon lacaniano el fundamento de un concepto potencial, capaz de recoger lo esencial que de la maniobra sofística ha socavado desde siempre la labor del filósofo. Naturalmente, Badiou dio el paso siguiente en ese sentido y concluyó que la praxis psicoanalítica, en tanto antifilosofía, quebranta el propio ejercicio filosófico. Un amenazante sofisma comenzó a advertir en la enseñanza lacaniana, que consideraba refugio de un peligro inminente para los filósofos que se acercaran, incautos, al campo psicoanalítico. Ante tal riesgo, nuestro autor lanzó un contundente llamado de superación: "Yo llamo filósofo contemporáneo a todo aquel que tiene el valor de atravesar sin flaquear la antifilosofía de Lacan" (Badiou, 2002, p. 187).

Fue así como el filósofo de "La Filosofía", el mismo de los manifiestos militantes, le impuso a la filosofía de su tiempo una tarea que tiene que todo que ver con el psicoanálisis. Aquella sentencia no era menor: la filosofía contemporánea está forzada a superar la antifilosofía lacaniana, está impelida y obligada a ello; si no, no se es filósofo hoy. Al seguir este camino no se intuye sólo el puro planteamiento de una desproporción entre ambos campos, sino la punzante sugerencia de que una suerte de oposición excluyente entre filosofía y psicoanálisis los condena a un enfrentamiento fatal.

Partiendo de la hipótesis de que, a diferencia de lo que opina Badiou, la filiación antifilosófica de Lacan no implica la promoción de un duelo de ultimidades entre el dispositivo analítico y el campo filosófico, contrastaremos sus respectivas nociones de lo real para distinguir la concepción badiousiana de la antifilosofía del sentido que pudo haber tomado este significante al interior de la enseñanza lacaniana. 


\section{Badiou: de la antifilosofía lacaniana a la ontología matemática de lo múltiple puro}

El recorrido badiousiano en torno a la antifilosofía lacaniana comenzó formalmente en su seminario de 1994, curso que se abrió al público con una puntualización inusual: el antifilósofo que se abordaría ese año -si bien era el único que se había declarado explícitamente como tal- no había destituido la categoría de la verdad ni le había abierto las puertas con simpleza al misticismo o al silencio.

A diferencia de Nietzsche y de Wittgenstein, para Badiou, Lacan "mantuvo un largo y tortuoso coqueteo con la categoría de la verdad" (Badiou, 2006, p. 47) que lo llevó a refundarla, pero anclándola en el despliegue de un acto que al mismo tiempo hacía preciso atravesarla. El maestro francés del psicoanálisis no dudó en "formular una oposición global entre [...] lo que se origina en Platón, y el verdadero sentido del invento freudiano" para derivar una serie de quejas gnoseológicas, éticas y ontológicas (BCIF, 2011). Sin embargo, según Badiou, su estrategia formaba parte de un movimiento más amplio -el antifilosófico- cuyas características fundamentales pueden reducirse a tres puntos: (1) el supuesto de que la cuestión del ser o la del mundo es una extensión de la cuestión de la lengua -la verdad queda así reducida a un efecto lingüístico o retórico culturalmente específico que por lo tanto debe ser juzgado-; (2) una apelación a lo que está más allá del lenguaje -en el límite superior de lo decible- como un dominio de significado, sentido, o conocimiento que es irreductible a cualquier forma de verdad, tal como se define en filosofía; y (3) la búsqueda de un acto radical con el que sea posible acceder a este dominio, y que por ende, desacredita de antemano cualquier elaboración sistemática, teórica o conceptual (Bosteels, 2008, p. 161). A partir de tales rasgos, Badiou (2006) definió la antifilosofía como "todo dispositivo de pensamiento que oponga la singularidad de su acto a la categoría filosófica de la verdad" (p. 45).

No sería desacertado afirmar que el fundamento primero de toda forma de antifilosofía se remonta, para Badiou, a la consideración del lenguaje como morada del ser. El origen del arte sofístico no es otro que la pervivencia del lenguaje como fuente de descentramiento y de pérdida de la verdad. Lacan, al organizar su enseñanza afirmando que el pensamiento funda el ser sólo 
anudándose en la palabra, mantuvo su gesto demasiado soldado al lenguaje, al punto de concebir la lengua como una prisión de la que no hay escape, opina Badiou. El problema de esta tentativa, a su entender, es que la verdad sólo puede ser allí un efecto lingüístico o retórico, en cuyo caso no sólo es factible declarar la imposibilidad de todo acceso a la verdad, sino que podría llegar a afirmarse que precisamente por esa imposibilidad, no vale la pena continuar filosofando.

No obstante, Badiou reconoce que una vez que se topa con los límites del lenguaje Lacan no abandona el concepto de verdad, aunque su compromiso lingüístico continúa alojando un peligro inminente: eventualmente invitará -por un camino sutilmente distinto del sofístico- a sustituir el ejercicio de la filosofía por la acometida de un acto personal fundado en una certidumbre anticipada (Badiou, 2006, p. 45). Allí inaugura su vereda antifilosófica. Lo esencial para los antifilósofos es del orden del acto y no de la proposición verdadera, su interés es "desacreditar la verdad, no refutarla" (Badiou, 2006, p. 47) y para ello acuden el acto, no como una acción de la verdad, sino como un fulgurante movimiento privado del que sólo se puede estar seguro por sus efectos. Allí, el concepto de acto se convierte para Badiou en el núcleo del litigio entre psicoanálisis y filosofía. Sus promotores suponen que la 'certidumbre anticipada' que lo inspira es predominante frente a la verdad en tanto que se ofrece como único acceso a ese espacio que preservan más allá de los límites del lenguaje, donde reside una promesa de conocimiento que es irreductible a la verdad. Para Badiou, la sola prefiguración de un espacio tal y el recurso a la potencia de un acto insondable que haga posible la entrada a él, destituyen la pretensión filosófica de la verdad en favor de una experiencia personal intrasmisible (Badiou, 2006, p. 47).

Así pues, la principal objeción que Badiou le plantea a la antifilosofía es su resignación de la tarea que permitiría erigir un sistema filosófico capaz de tornar transmisible la verdad con independencia de las experiencias personales y subjetivas de los individuos. A su juicio, el hecho de que ningún lenguaje pueda traslucir lo que es sin cosificarlo y convertirlo en algo distinto de sí mismo, no significa que deba desestimarse la posibilidad de otorgarle un tratamiento lógico, sistemático -y no experiencial- al problema del ser-en-tanto-ser. Badiou suscribe las críticas anti- 
objetivistas de las corrientes filosóficas derivadas del giro lingüístico, así como también dice plegarse a lo adelantado por Lacan sobre la desproporción entre la verdad y lo real, sin embargo, asegura que ambos derroteros conducen a un mismo callejón sin salida por considerar el leguaje como "la casa del ser". De antemano y sin excepción acaban por condenar al fracaso cualquier intento de ontología.

En ese sentido, la propuesta badiousiana recurre al concepto de acontecimiento para aludir a la universalidad infinita que escapa al cierre de cualquier situación estructurada y legitimar así un tipo de pensamiento sobre el ser que sostenga la verdad como categoría operatoria (Lüders, 2010). La verdad puede existir sin tocar el lenguaje si se concibe como el resultado material de una fuerza militante que reunió ciertos términos forzando el acontecimiento. Tal como afirma Laclau (2004), lo que Badiou construye en ese sentido es una ontología dualista de base estructural que le permite formalizar principios abstractos despojados de la lengua. El filósofo franco-marroquí hace aparecer la verdad como una consistencia subjetiva que hace agujero en el saber, y al sujeto no como una estructura dada -de conocimiento o de desconocimiento- que preexiste al acontecimiento, sino como el principio formal de cierta configuración corporal material, como una parte infinita de la verdad que emerge de la inconmensurable distancia teórica que separa al acontecimiento de la situación en la que tiene lugar.

Asimismo, esta noción de la verdad guarda una concepción especial de lo real que remite de inmediato a la ontología. Según Badiou, el filósofo que se haya dejado educar por la sofística del siglo XX, sabrá que de lo que se trata hoy en lo que respecta a la ontología no es de insistir en un fundacionalismo imposible, sino de "marcar los límites radicales de lo que el lenguaje puede constituir" y, en consecuencia, “asumir lo múltiple" (Badiou, 1990, p. 73). Es necesario redefinir el quid del discurso ontológico tras los duros avatares del siglo pasado, y la noción de vacío vendrá a ser para Badiou el operador conceptual que lo permita. Su propuesta consistirá en abrir la posibilidad de decir qué insiste allí donde ya nada puede ser dicho: "algo pasa pero su pasar no se sostiene en la lengua: es lo que no es" (Celedón, 2010). 
En su intento por levantar una teoría postcartesiana, postheideggeriana y postlacaniana del ser y la verdad, nuestro autor empleó la marca escandinava ' $\varnothing$ ' para nominar el punto de detención al que llega el pensamiento cuando la sofística extirpa la verdad del mundo. No es una impostura la denuncia del antifilósofo que señala la sustracción del ser al lenguaje, pero lo que aparece toda vez que se evidencia la imposibilidad de sostener la adecuación entre el ser y lo uno, no es sólo la propia falla de lo uno, sino la estela de su anterioridad insondable. Para Badiou, algo emerge como resto discernible del 'hay uno' que presenta toda situación: un recóndito lugar donde persiste el vacío como fundamento originario. Es el ser-en-tanto-ser que, bajo la forma de un 'sería', se aprehende retroactivamente como pura multiplicidad irreductible, inconsistente e inestructurada (Badiou, 2003a, p. 78). Un impresentable que se conquista sólo en el pensamiento y al que conviene denominar 'vacío' por encarnar la mera inferencia que se alcanza al remontarse a la anterioridad lógica de cualquier situación estructurada.

Es preciso entonces asumir que en la filosofía badiousiana el vacío se constituirá como el nombre propio del ser-en-tanto-ser, ante la mera presuposición de que 'antes' de la cuenta, lo uno no es (Badiou, 2003a, p. 67). La ontología resultante de la afirmación de que lo uno no-es no será, por tanto, una ontología de sustancias, o de la nada, sino del puro 'habrá-sido-contado' que se discierne como efecto de la cuenta. Allí el autor exhibe su particular forma de apropiarse de la enseñanza lacaniana, pues al postular que el ontólogo debe tratar con el nombre de la impresentación en la presentación, éste se incluye en la situación indicando lo que se pensaría si la ley del uno lo autorizara: que lo uno no es, que el ser de la consistencia es la inconsistencia, o lo que es lo mismo, que la cuenta-por-uno supone la existencia de un real no simbolizable adherido por su causa a toda presentación simbólica.

En ese sentido resulta iluminadora la aclaración de Bell (2011, p. 105): “la ontología matemática de Badiou entiende la categoría [lacaniana] de lo real como el nombre del ser-en-tantoser". Efectivamente, Badiou se asigna la tarea de rescribir el concepto del real lacaniano, no como una ausencia subjetiva, sino como una consistencia efectiva que se sustrae al saber y que en esa 
medida designa al objeto clásico de toda ontología. Lo real para Badiou se puede hacer consistir como sujeto de la operación subjetiva que nomina el acontecimiento, de modo que el filósofo ha de prescindir de la concepción de lo real como causa, como dislocación del orden simbólico, para pensarlo como consistencia que inscribe un procedimiento genérico de la verdad (Farrán, 2009, p. 7).

Como bien señala Hallward (2003), el platonismo de Badiou, en contraste con el platonismo clásico, supone la univocidad vacía de la pura multiplicidad como la única provincia de la ontología. En ese sentido, Badiou sostendrá contra diversas tradiciones filosóficas que la ontología es una situación que comprende la inexpugnable sustracción del ser (Badiou, 2003a, p. 36). Pero ¿qué clase de discurso sería capaz de disponer las condiciones bajo las cuales el ser se deja reconocer en tanto tal, esto es, como im-presencia? "La tesis inicial de mi emprendimiento [...] es la siguiente: la ciencia del ser-en-tanto-ser existe desde los griegos, ya que tal es el estatuto y el sentido de las matemáticas" (Badiou, 2003a, p. 11). Para Badiou, la matemática es el único discurso capaz de mostrar en qué condiciones se estructura lo múltiple sin definirlo, sin producirlo como uno, es decir, prescribiendo lo que no acepta.

El carácter antifilosófico del psicoanálisis está en juego de forma privilegiada precisamente en ese punto que concierne a lo real. Proveniente del vocabulario de la filosofía y emparentado con el concepto freudiano de 'realidad psíquica', lo real es tomado por Lacan como una realidad fenoménica inmanente pero imposible de simbolizar (Roudinesco y Plon, 2008, p. 923). Siguiendo a Miller (2011), en la época de La carta robada aparece como la eficacia efectiva del significante, como una especie de "real-orden" que remite al orden simbólico anudado por una ley. Pero a partir del Seminario XI, lo real se desengancha del orden para convertirse en lo que el pensamiento no encuentra, en lo que no obedece a ley. Desde entonces, lo simbólico queda del lado del automaton y lo real de la tyche. Es el momento en que frente al real-orden, aparece el real-trauma, lo real como agujero negro inasimilable (p. 29). 
Al toparse con la concepción lacaniana de lo real, Badiou vio renacer sin más las tesis de la sofística clásica: lo existente no puede ser pensado y si pudiera, sería incomunicable a los demás. Pero persuadido por el recurso lacaniano al matema como modelo de la formalización en psicoanálisis, distinguió un ideal que podría fungir como gozne entre sus versiones de filosofía y psicoanálisis: el del tratamiento de "lo que no se dice pero puede transmitirse" (Lacan, 2008b). El filósofo asegura que Lacan no es Kant, "pues si bien no conocemos lo real, ello no significa que sea incognoscible" (Badiou, 2006, p. 57). Su tesis establece que pese a la sustracción de lo real al conocimiento, Lacan sostiene la posibilidad de abrir un acceso demostrativo a lo real a través del matema, que permitirá afirmar el trasfondo ontológico de la incognoscibilidad sin desmedro del obstáculo que el no-ser supone para todo pensamiento que intente definirlo:

Platón se había equivocado, nos dice Lacan, al llenar al ser de saber. Pero el matema autoriza un llenado inacabable muy distinto: llenar del vacío mismo que los disyunta a lo in-sabido y al saber. En tal sentido, habría saber de una verdad in-sabida, en el punto del vacío. Y, en consecuencia, el acceso al ser, al igual que en filosofía, estaría en la suposición de un vacío que no fijan sin resto, y por lo tanto sin pleno, más que las letras pequeñas de la formalización (Badiou, 2002, p. 269).

La comunicabilidad del ser deja de ser allí pura imposibilidad y se abre un nuevo horizonte para la filosofía contemporánea que, a contramano de la antifilosofía lacaniana, se erige como capacidad afirmativa de un universal que se sustrae al saber:

Nada me liga más a la enseñanza de Lacan que su convicción de que el ideal de todo pensamiento consiste en lo que de ese pensamiento puede transmitirse universalmente fuera del sentido. O sea, que lo insensato es el atributo primordial de lo Verdadero (Badiou, 2008, p. 575-576).

Ser lacaniano es, pues, ir más allá de Lacan y completar lo que el psicoanalista 'intuyó' con su máxima del medio-decir: 


\begin{abstract}
Estamos pues seguros -puesto que, como lo dijo en repetidas ocasiones Lacan, la matemática es ciencia de lo real- de que es muy real esta singular sustracción al marcaje de lo múltiple puro por el efecto de lo Uno de la lengua (Badiou, 2002, p. 176).
\end{abstract}

Este recorrido dibuja el panorama de la relectura badiousiana de Lacan. El matema como ideal de formalización vendrá a garantizar la transmisión de ese incomunicable insensato que, no obstante, es captado como ser-en-tanto-ser toda vez que el filósofo dirige su mirada al fondo que delata la ruptura simbólica. Ciertamente, en la década de los 70, Lacan "trataba de arrancarle el saber a lo inefable para darle una forma íntegramente transmisible" y "esa forma era el matema" (Roudinesco y Plon, 2008), pero es necesario recordar que éste nunca fue el lugar de una formalización integral al modo como la concibe Badiou, puesto que, al igual que la letra, siempre supone un resto que se le escapa (p. 923).

\title{
Lo real, otra vez: De Lacan a Badiou.
}

La filosofía de Badiou rearticula ontológicamente las estructuras lacanianas como procesos de verdad, reformula lo real como multiplicidad inconsistente y convierte a las matemáticas en el único lenguaje ontológico idóneo para tratar aquello que el psicoanálisis puso de manifiesto como real. Al respecto, pocos autores se han abocado a demostrar que el real de la experiencia analítica insiste en su contraposición a esa extensión ontológica de la enseñanza lacaniana; no obstante, en lo sucesivo veremos que el desarrollo badiousiano dice más del impacto que tuvo Lacan sobre el trabajo del filósofo, que del psicoanálisis mismo como praxis, donde lo real no aparece sino como el quiebre mismo de todo discurso ontológico.

Cassin (2013) ha desarrollado un recorrido por el pensamiento de Lacan que arroja luces preciosas sobre la relación que el psicoanalista sostuvo con la filosofía. Su reflexión, que comienza y culmina justo donde emergen los confines en los que se encuentran Gorgias y Lacan, nos ofrece el 
hilo conductor idóneo para iluminar la cuestión de la antifilosofía entre Lacan y Badiou a partir de la noción de lo real.

Los fundamentos del psicoanálisis y su inscripción por parte de Lacan en la lógica del significante replican, a su manera, las populares tesis del Tratado del no-ser con el que Gorgias objetó el eleatismo ontológico. Dice la autora: "Frente a la ontología, la tesis sofística y la tesis lacaniana forman una unidad: el ser es un efecto de decir, 'un hecho de dicho'” (Cassin, 2013, p. 57). La primera tesis del sofista - "El que dice, dice un decir" (Gorgias, en Sextus, VII, citado en Barrio, 1980)- promueve una reducción fundamental del ser que reaparecerá en la enseñanza lacaniana -“Quien habla, habla” (Lacan, citado en Cassin, 2013, p. 58)-. Sobre este principio fundamental, Gorgias derivó su segunda tesis que consistió en afirmar que lo que existe es disimétrico de lo pensado, anticipando de forma sorprendente la subversión freudiana de la transparencia del cogito en la que se asienta el supuesto de su identidad con lo real. Finalmente, en su tercera tesis estableció una distinción entre la palabra y lo real que fue fundamental para refutar el falso privilegio que ostenta todo discurso sobre el ser. Como apunta Cosentino (2016), esta última tesis no "niega la existencia de las cosas (prágmata), sino la posibilidad de comunicarlas y, en consecuencia, la supremacía del lógos como instrumento"; sin embargo, para el autor, "sigue operando en el pensamiento de Gorgias la existencia de cosas por fuera de las palabras, aunque no puedan ser comunicadas", lo cual lo lleva a afirmar que en ese punto Lacan no es Gorgias (p. 126).

La lectura de Cassin y Cosentino sobre la afinidad sofística del psicoanálisis nos permite afirmar, frente a Badiou, que Lacan no guarda lo real como objeto en un afuera pre-discursivo que en esa medida supone incomunicable. Lo real no es una existencia consistente que pervive fuera del discurso; pero creemos necesario decir que tampoco lo es para Gorgias. Allí discrepamos de la distancia que Cosentino advierte entre Gorgias y Lacan. El estatuto que para el sofista de Leontinos cobra lo existente como algo que tiene su realidad fuera de nosotros, no proviene de su consideración como subsistencia cerrada, anterior e independiente del lenguaje, sino de su desproporción con respecto a la palabra, esto es, del hecho de que la palabra no se adecúa 
plenamente a la existencia (Barrio, 1980, p. 117). Lejos de resguardar el ser -o el no ser- como una realidad pre-discursiva, Gorgias afirma un real que existe a contrapelo del ser. He allí el primer pilar de una contestación posible al esfuerzo badiousiano de erigir una ontología -de inspiración lacaniana- sobre el no-ser. La estrategia sofística que destituye al ser de su lugar privilegiado por considerarlo 'un efecto del decir' despliega una doble afirmación que es significativamente más radical de lo que Badiou logra reconocer: la palabra no puede alcanzar lo real, y ello, lo que existe que evidentemente no es del orden del ser ni del no-ser- "no manifiesta su recíproca naturaleza" (Gorgias, en Sextus, VII, citado en Barrio, 1980, p. 144). En este escenario, lo real como existencia se contrapone al ser-comunicable, que desde luego no es más que el vano intento por captar y decir lo que existe. Podríamos decir entonces que el ser de los sofistas aspira, en secreto, a la existencia.

Si bien es cierto que Lacan y Gorgias se encuentran en una impugnación de Parménides que implica la puesta de manifiesto del ser como un efecto del discurso, puede observarse que con ello no pretenden reedificar la identidad entre el ser y lo real, sino partir precisamente de su disparidad para afirmar una tesis dual que concierne a la ontología: lo que comunicamos no es lo real, y lo real no puede, en última instancia, ser comunicado. Es a lo que Lacan se dirige toda vez que afirma que no hay metalenguaje. Allí se evidencia que tal como indica Badiou, Lacan tampoco es Kant, pero no porque lo real no sea incognoscible -que lo es-, sino porque en tanto incognoscible no es un noúmeno; es la irrupción como forma fenoménica del tiempo que existe allí donde un sujeto la encuentra (tyche).

Retornar a Gorgias en este punto es esclarecer, frente a Badiou, la especificidad de la tentativa lacaniana en su tratamiento de lo real y, por ende, su relación con la ontología. Sin embargo, los principales avatares de este asunto en el pensamiento lacaniano se encuentran desplegados en el Seminario 11, donde la digresión sobre el estatus conceptual de las nociones sobre las cuales Freud cimentó su campo, trasluce el postulado central que hermana el decir lacaniano con el de Gorgias: lo que existe no es un ser, por tanto, ser no es lo mismo que existir. Esta premisa constituye el fundamento de lo que será una progresiva caracterización del 
psicoanálisis como un discurso otro de la ontología tradicional, que Lacan impugnará, a sus efectos, por haber actuado dándole al ser su estatuto por fuera del orden significante. El programa que allí despunta se cristalizará en el Seminario 20, cuando Lacan haga explícita su renuncia a referirse al ser -su renuncia a la ontología- para privilegiar el registro de lo real que, si seguimos a Miller (2011), no es otro que el de lo que existe (p. 72).

En el Seminario 11, "el carácter demasiado olvidado [...] de la primera emergencia del inconsciente" (Lacan, 2008a, p. 38) es invocado para referir una existencia cuyo régimen consiste en "no prestarse a la ontología" (p. 38). 'Lo que hay', en este texto, aparece ligado al inconsciente como presentación, respecto de lo cual dice Lacan que "la discontinuidad es la forma esencial en que aparece en primer lugar el inconsciente como fenómeno" (p. 33). En el tropiezo, en la falla de una frase pronunciada o escrita, Freud capta "una cosa distinta que exige su realización" y que aparece con una extraña temporalidad bajo la forma de la discontinuidad. Surge entonces una primera advertencia lacaniana que parece tomar como referencia a la ontología para formularse: naturalmente, la irrupción de una fisura tal despierta la tentación filosófica de colocarla sobre el telón de fondo de algún tipo de totalidad, pero sólo si se busca extraer de Freud un "psiquismo de envoltura" en el que una profundidad total y consistente -así sea de multiplicidades- subyazca a las manifestaciones discontinuas, se verá en el real que pone de manifiesto lo inconsciente un uno anterior a la discontinuidad (Lacan, 2008a, p. 33).

Por su parte, hemos visto que, anteponiendo su inspiración lacaniana, Badiou asegura que toda ontología que pretenda ser compatible con la sustracción del ser demostrada por la sofística, ha de afirmar como real ese 'resto' inaccesible al pensamiento que tiene lugar en el lugar, esto es, el uno de la multiplicidad im-presentada al que se dirige la inferencia del ontólogo tras toparse con la discontinuidad. Ciertamente, en el Seminario 11 se aprecia que el psicoanálisis hace brotar como existencia el uno de lo no-consciente (Unbewusste), pero con la misma radicalidad con la que explicita lo que hay de real en las formaciones del inconsciente, Lacan (2008a) discierne la presencia de un límite predominantemente conceptual en su formulación: "el límite del Unbewusste es el 
Unbegriff", que podríamos traducir como el in-concepto o como "el concepto de la falta" (p. 33). Esto es decir, a nivel de la formalización, que el uno de lo no-consciente que la experiencia analítica distingue como existencia, está limitado por una función -la de la falta- que lo hace resistente a la finitud impuesta por toda captación teórica, temporal y espacial, tanto más cuanto que tiene todo que ver con el modo en que se presenta de facto el inconsciente freudiano, y no con lo que es en el fondo. Haciendo resonar las cuerdas sofísticas, Lacan ubica en el centro desconocido que encuentra la exploración freudiana un límite onto-lógico que le impide avenirse al discurso sobre el ser que, no sin error, puede llegar a suponérsele.

Más específicamente, la enseñanza lacaniana se escribe en tensión con la tentativa badiousiana en la medida en que, en su intento de leer aquello de lo que se trata en psicoanálisis como el núcleo de una nueva configuración ontológica, ignora que la existencia que la experiencia analítica atestigua no pertenece al orden del ser ni al del no-ser, sino al de algo que exige siempre su realización: "lo primero que se le hizo patente a Freud [...] es que lo que pertenece propiamente al orden de lo inconsciente [...] no es ni ser ni no-ser, sino no-realizado" (Lacan, 2008a, p. 38). El uno que la experiencia del inconsciente introduce es el uno de la ranura, de la ruptura, y no el de la multiplicidad realizada ni el del vacío fundamental que no por in-consistente deja de conceder a la función del tiempo. La reconceptualización badiousiana del real lacaniano como trasfondo ontológico de la supuesta no constructibilidad de la verdad, refleja una nueva forma de la misma tentación previa: pensar que hay un telón de fondo sobre el cual ocurre la discontinuidad: unafalta-de-consistencia tan completa, autosuficiente y envuelta como la anterior. En ese sentido, la inconsistencia que dispone como objeto de la ontología no puede dejar de aparecer como una existencia pre-discursiva.

Bajo estas coordenadas, la ontología matemática de lo múltiple puro no ofrece más que una renovada forma imaginaria de encerrar en nuestra temporalidad aquello que la excede. Al declarar que "el estatuto del inconsciente es ético y no óntico", Lacan desinfla la esperanza de extraer del psicoanálisis una ontología de cualquier tipo - del ser, del no-ser o de la nada- en la medida en que 
el telón de fondo apriorístico que este discurso implanta en lo real, surge sólo como ausencia -para un sujeto que tiene otras expectativas- tras la ruptura que constituye lo inconsciente (Lacan, 2008a, p. 34). Al igual que en el programa gorgiano, en psicoanálisis no se trata de negar lo real, sino su equiparación al ser-en-tanto-ser del que se hace discurso, y por ende, la posibilidad de tramitarlo integralmente mediante alguna suerte de lenguaje superior. Lo real no puede ser dicho como ser puesto que no consiste como éste en el discurso, sino que irrumpe en él para hacerlo vacilar; de allí que Lacan conciba el ser como semblante (Miller, 2011, p. 71), y no como un dominio de sentido que aguarda la llegada de un acto subjetivo capaz de capturarlo efectivamente.

No obstante, ese punto de no-ser llamado vacío que en la filosofía badiousiana insiste como una pre-existencia ontológica, no es el único elemento de su ontología que resulta incompatible con el pensamiento lacaniano. Allí donde la matemática reintroduce la intención de tramitar y transmitir lo que no-es, la sofística no cesa de revelar su carácter performativo, que se acentúa toda vez que se hace explícito el punto en que el matema se encuentra en la misma situación que la palabra.

La grafía ' 1 ', lo mismo que ' $\varnothing$ ' o que la expresión ' $2+2=4$ ', es formalización de un aprehensible que sólo se vuelve tal en su propia creación discursiva. Pero al trazar el camino que conduce de lo real como causa a lo real como consistencia, Badiou desconoce que lo que se piensa por la vía de lo que consiste al in-consistir se trata como si siempre hubiera estado allí. En el Seminario 20 Lacan puso en claro el motivo de su filiación a las matemáticas mediante un movimiento que, muy lejos del ideal badiousiano de la transmisión integral, parecía reescribir a cabalidad -pero esta vez respecto del matema- la primera tesis del Tratado sobre el no ser:

Nuestro recurso es, en lalengua, lo que la quiebra. Tan es así que nada parece constituir mejor el horizonte del discurso analítico que ese empleo que se hace de la letra en matemáticas. La letra revela en el discurso lo que, no por azar ni sin necesidad, se llama gramática. La gramática es lo que del lenguaje sólo se reserva en lo escrito. Más allá del lenguaje, ese efecto, que se produce por tener su soporte sólo en la escritura, es ciertamente el ideal de las matemáticas (Lacan, 2008d, p. 58). 
Entre esta formulación y la afirmación badiousiana que define las matemáticas como "el sistema de condiciones a través de las cuales lo múltiple se deja reconocer como múltiple" (Badiou, 2003a, p. 39), existe un abismo sutil. Cosentino (2016) se expresa bellamente cuando afirma que "Gorgias nos pone de manifiesto que el héroe del poema de Parménides -el Ser- es un efecto del poema mismo" (p. 125), pero Lacan no escatima al de desplegar los alcances de tal efecto de discurso. El anuncio de que para el psicoanálisis "la formalización matemática es el ideal" adquiere su valor en contraste con la imagen del objeto significativo que el lenguaje asegura; el analista acude al matema porque allí se encuentra "apelando a una ocurrencia que no quiere decir nada" (Miller, 2011, p. 71). Frente al semblante de un objeto -llamado ser- al que se le supone un sentido, el matema viene a ofrecerle al psicoanálisis la oportunidad de transmitir la pura ley que lo rasga. El matemático toma la letra como reveladora de las normas que gobiernan el discurso del cual forma parte, y no como prueba de la anterioridad supuesta -semántica o asemántica- que puede llegar a colegirse de ella. De allí se desprende que, al contrario de lo expuesto por Badiou, el psicoanalista recurre las matemáticas precisamente por su relación de alteridad con respecto a la ontología, a saber, en virtud de que lo único que puede revelar el matema es su propio logos -y no las cosas que son, ni los seres sensibles que las lenguas, incluso la suya, producen como idea-.

Aunado a ello, Lacan introduce un punto de excepción al ideal de matematización que justo allí donde es coherente con su tesis sofística capital -la ausencia de metalenguaje-, subvierte toda posibilidad de convertir la matemática en un verdadero lenguaje del ser, esto es, en una escritura sobre las formas del lenguaje que se sostenga por sí sola:

La formalización matemática es escritura, pero que no subsiste si no empleo para presentarla la lengua que uso. Esa es la objeción: ninguna formalización de la lengua es transmisible sin el uso de la lengua misma. A esta formalización, ideal metalenguaje, la hago ex-sistir por mi decir. Así, lo simbólico no se confunde, ni de lejos, con el ser, sino que subsiste como ex-sistencia del decir (Lacan, 2008d, p. 144). 
Una consecuencia crucial que se desprende de la identidad que establece Badiou entre las matemáticas y la ontología es que "la filosofía está en su origen separada de la ontología" (Badiou, 2003a, p. 22). Para el filósofo franco-marroquí, la ontología "existe plenamente" y su campo de acción queda delimitado por el ejercicio matemático que permite que lo que es posible decir $-\mathrm{y}$ lo dicho- sobre el ser-en-tanto-ser no dependa, de manera alguna, de la lengua. Sin embargo, como bien señala Hallward (2003), en ese sentido "El ser y el acontecimiento es un tratado filosófico más que matemático" (p. 82). Pese a esa distinción que procura darle a las matemáticas la independencia discursiva que requieren para constituirse como metalenguaje, toda la obra filosófica de Badiou se resuelve en un claro francés - de no pocas resonancias poéticas- que no deja de disponer una a una las condiciones bajo las cuales puede pensarse al ser-en-tanto-ser y a las matemáticas como lenguaje del ser. Su trabajo filosófico es muestra en acto de que la operación del matema no se sostiene sin una lengua natural que la 'diga', lo cual no sólo distancia sus pretensiones y su conceptualización del matema del uso que recibió este operador en el campo psicoanalítico, sino que trunca la posibilidad, desde la perspectiva lacaniana, de que las matemáticas solucionen la imposibilidad metalingüística del discurso ontológico.

El reverso de aquella puntuación lacaniana no es menos revelador. Allí donde escribir las formas del lenguaje "no basta para asegurar el ser del metalenguaje", se revela que entonces éste no puede extraer su potencia sino de aquello sobre lo cual versa. Es lo que lee Cassin en la afirmación de Lacan: "El discurso del ser supone que el ser sea, y esto es lo que lo sustenta" (Lacan, 2008d, p. 144). Lo que toda ontología produce en tanto discurso es su propia consumación (Cassin, 2013, p. 59) y he allí una objeción que no supera ni el matema como ideal del psicoanálisis. Sea lo que sea que advenga de la ontología, incluso de las matemáticas tomadas como ontología -una totalidad consistente o una multiplicidad de multiplicidades-, tendrá siempre el poder de realizarla como discurso de ello, y allí reside el fundamento de una deriva de sentido, que es en todo, contraria a las pretensiones del discurso analítico. 
Este panorama demuestra que la relectura de lo real por parte de Badiou, aglutinado en el matema, no sólo no comprende el real lacaniano sino que aniquila su posibilidad. Nuestro autor no recurre al campo matemático para hallar en él lo que quiebra la lengua, sino muy por el contrario, la inferencia deducible que en última instancia es lo que funda, en secreto, la posibilidad de todo discurso ontológico. En ese sentido, pese a su reformulación del ser-en-tanto-ser como un vacío insensato, la ontología de lo múltiple puro sigue tan adscrita al régimen parmenídeo del sercomunicable, como a la adaecuatio entre el ser y lo uno que el propio Badiou quiso proscribir, y esto es así porque sigue siendo ontología en el sentido clásico: olvida que "el sentido [del ser] sólo puede ser aprehendido après coup, habida cuenta del mundo que produjo" (Cassin, 2013, p. 58). Los postulados badiousianos silencian un sentido unario no explícito que, no obstante, no pueden dejar de presuponer, y además, en la medida en que propone deducir de ciertos signos matemáticos un no-saber pre-escrito, Badiou le sigue otorgando a la matemática la prerrogativa que Lacan exilió del mundo: su poder para traslucir lo propio de esa ilusión que inconfesadamente produce como justificación suya.

Voy a decir -es mi función- voy a decir una vez más [...] algo que es de mi decir, y que se enuncia: no hay metalenguaje. Cuando digo eso, quiere decir, aparentemente, no hay lenguaje del ser. ¿’Pero hay ser? Como señalé la última vez, digo lo que no hay. Ese ser, no se hace más que suponerlo a ciertas palabras [...]. Para mí, no es más que un hecho de dicho (Lacan, 2008d, p. 143).

Trátese del ser o del no-ser, la palabra, al igual que el matema, tiene para el psicoanálisis, al igual que para la sofística, una realidad distinta de lo real. Por tanto, lo que aspira a comunicar es radicalmente indecible en tanto tal. La propuesta de Badiou no escapa a esta impugnación. Allí donde Gorgias elucida el carácter truncado de la ontología, Lacan retorna al punto que el descubrimiento freudiano del inconsciente pone de manifiesto como ruptura del orden simbólico, para afirmar que su decir se distingue de todo tipo de lenguaje sobre el ser (Lacan, 2008d, p. 144). Badiou y Lacan concuerdan en que el ser no puede más que ser un supuesto, pero el filósofo lo 
independiza de la lengua para otorgarle, por un lado, una realidad sólida y subsistente, y por otro, para investir al metalenguaje matemático con el poder autónomo y cabal de referirse a ello. A distancia de ello y deudora punto por punto de la sofística gorgiana, la referencia lacaniana a la ontología se abstiene de hacer sentido a partir de la letra/matema, pudiendo sólo ser concebida como una ausencia en segundo grado, esto es, como la pura y límpida afirmación de que no hay metalenguaje.

Ahora bien, lo simbólico, lo imaginario y lo real operan en la palabra de quien se sitúa en el discurso analítico (Lacan, citado en Cassin, 2013, p. 59). De allí la vecindad del psicoanalista y el filósofo. Hay algo que puede designarse bajo estos términos para darle claridad a la experiencia analítica, pero al hacerlo resulta inmediatamente necesario situar sus referentes tal y como en ella aparecen: como producto, como efecto del decir. Lo que resulta en consecuencia no es una negación existencial del ser-en-tanto-ser, sino una modificación de su estatuto y, por lo tanto, un esclarecimiento de lo que esta última expresión designa al interior del discurso psicoanalítico: una “concreción fetichizada de soplo, solamente por haber sido discurrido" (Cassin, 2013, p. 59).

“[...] El matemático nunca piensa sin objeto. Más aún, afirmo que es el único hombre que piensa un objeto por completo desnudo". [...] una vez propuesto ese objeto, no hay esperanza alguna de vencerlo, quiero decir, de fundirlo, disolverlo, cambiarlo, volverse dueño de él, en fin, por otro medio que no sea el del justo y exacto conocimiento y el manejo correcto de lo que de él resulte (Alain, citado en Miller, 2011, p. 60).

En estas líneas escriben una elucidación diáfana de la relación de objeto que revela la afinidad entre las matemáticas y lo real. Una relación que Lacan llamó 'fantasmática' por cuanto el fantasma es el garante modal de la sujeción del ser hablante a su objeto de deseo. La aspiración que resalta Alain además de Badiou- nos revela el quid del juego ontológico matematizado: la producción de un seren-tanto-objeto al entendimiento que remite sin cesar a la función del deseo, en la medida en que no se constituye sino en la propia aspiración de apropiación que se cierne sobre él. Así, la forma en 
que la relación de objeto fue trabada en la época en que Lacan hablaba de "atravesamiento del fantasma", ilumina la función de la ontología en psicoanálisis.

"El efecto mayor de la experiencia analítica viene en términos de revelación ontológica" (Miller, 2011, p. 26) toda vez que entre la palabra y su objeto hay una soldadura contingente que en determinado momento del análisis el sujeto logra cuestionar. A lo que eventualmente llega el analizante no es sino a dar cuenta de aquello en lo que consiste el acto ontológico: "que las categorías significativas que organizaron su mundo, no son otra cosa que eso: su mundo" (p. 26). Lo que allí adviene, en tanto subversión del olvido mismo que aloja la ontología, desencadena un movimiento retroactivo que en su cúspide alcanzará al deseo. Al revelarse la petición de principio en que se resuelve el discurso sobre el ser, el "no-ser que uno creía ser queda destituido de esta calidad", manifestándose por primera vez como des-er, como mero semblante de ser (p. 27) cuyo único poder y función consistía en sostener el deseo en torno a su fachada.

Así las cosas, la ontología no se constituye como tal sino por situar en el horizonte de su discurso un objeto agalmático, que brilla con la luz que le otorga una suposición que a la vez lo anima y cuya función es precisamente cubrir lo que lo causa: el propio goce (Miller, 2011, p. 27). Sea unario, múltiple, consistente o inconsistente, allí donde la ontología badiousiana va desde el noser hacia el ser-en-tanto-objeto, el análisis es la pantalla de un viraje que va desde el objeto hacia el des-er. Lo determinante es que lo que queda entonces del ser es la pura disipación de su significación; no una oposición o un derrocamiento, sino una discreta disminución que lejos de regocijarse en la caída de lo que albergaba de fe, o en la promoción universal de un acto resolutorio, dará nacimiento a un saber sobre ello. Es lo que Lacan elaboró como el pase: del ser del deseo (des-ser) al ser del saber (Miller, 2011, p. 27). Lo que surge allí no es, pues, sino lo que podríamos llamar una 'deflación de la ontología', esto es, un deflación del deseo del objeto que se ha revelado como no-siendo lo que fundaba el deseo que suscitaba.

Estas claves que proporciona Miller iluminan nuestro asunto especialmente. Mientras el psicoanalista se las ve con algo que se deja perturbar por la palabra, que es del orden de la retórica 
y que, en contraposición al objeto, sería más apropiado llamar la 'cosa -freudiana-' (Miller, 2011), bajo el decir de Badiou hay una filosofía objetual que detenta el sueño de la conquista de un ser que es tan compacto como reacio a la retórica. Lo que está en juego para Badiou es la disposición de un objeto que es impermeable a los efectos de la palabra y en torno al cual instala la militancia de amo del filósofo. Así asegura el escenario de un totalitarismo del deseo filosófico, donde lo que debe resguardarse es la adhesión de los seres hablantes a un objeto inconmovible que, como tal, está fantásticamente investido con la gracia de ser lo que es al no-ser.

\section{Por la especificidad del discurso: elogio de una tensión irreductible.}

Una serie de malos entendidos y desencuentros teóricos han conducido, según parece, el debate badiousiano con el psicoanálisis y sobre todo, su consideración de Lacan como un enemigo de la filosofía. Sin embargo, la indicación lacaniana que antepone la ética del psicoanálisis a su estatuto ontológico, hace evidente que la distancia entre Lacan y Badiou no reside sólo en cómo conciben lo real, sino sobre todo, en cuál es el oficio al que cada uno consagra su esfuerzo.

Muy lejos del consenso en torno al sentido que pudo haber tenido la enigmática referencia a la antifilosofía por parte de Lacan, diversos autores aseguran que hubo antifilosofía en su pensamiento desde 1969-1970 cuando, en paralelo a la formulación de los cuatro discursos, el psicoanalista anunciaba haber logrado finalmente "colocar en su lugar al discurso filosófico y a la verdad", vinculando al primero con su célebre discurso del amo (Escobar, 2011, p. 22; Balmès, 2002, p. 238).

La historia de la filosofía, por su parte, fue desde entonces para Lacan égida del discurso universitario, al que se refirió como fuente de un conocimiento que es ideología disimulada y que refuerza todo lo que pasa a ser el status quo del amo (Lacan, 2008c). En ese sentido, los versados en el tema han señalado que no por casualidad la insurgencia anunciada por Lacan contra la filosofía llegó en un momento en que sus circunstancias institucionales implicaban, más que nunca, asuntos relativos a la enseñanza y transmisión del psicoanálisis en contextos académicos (Johnston, 2010, p. 
138). Si en el discurso universitario "el saber ha ido a parar al lugar del orden, del mando" instalado el precepto: "Sigue adelante. Sigue sabiendo cada vez más" (Lacan, 2008b, p. 109-110), mientras que desde el discurso analítico se afirma que "lo irreductible a la letra es la orientación de todo el discurso, y [que] la letra en sí misma, tomada como objetivo supremo sólo producirá desorientación" (Márquez, 2011, p. 40), el psicoanalista no puede ocupar el lugar del maestro que profesa su maestría. No obstante, para Lacan era determinante que la experiencia analítica fuese transmisible.

Es en ese escenario donde aparece el hápax de la antifilosofía: respuesta a la necesidad de delinear la posición del analista en el recinto universitario y asegurar un lugar que le permitiera profesar sin introducir furtivamente el semblante de un saber total ni el mandato a conseguirlo. Inscrita en un discurso dirigido a los psicoanalistas, no por azar la primera mención del término que es categóricamente pedagógica- busca ofrecerles una herramienta que les permita aclarar aquello de lo que se han servido en su análisis personal, a saber, "la investigación de lo que el discurso universitario debe a su suposición 'educativa'” (Lacan, 2012, p. 333). No es poca cosa definir la antifilosofía como mero instrumento de análisis discursivo orientado a la localización del extravío que produce en el sujeto ese modo de vínculo social que lo sitúa como ser-pensante frente al semblante de un Otro que sabría lo que él debe perseguir. La transmisión del psicoanálisis comporta, por el contrario, lo irreductible a la letra, lo que se enseña sólo como rasgo aislado de la propia experiencia analítica (Bassols, 2017), y es en ese sentido que dicha transmisión acababa por ser, de cierto modo, lo opuesto a una enseñanza.

De haber una contraposición a la filosofía en este empleo del término, esta no puede, pues, sino reducirse a lo que desde el discurso psicoanalítico remite a un uso de las palabras que obstaculiza la transmisión de ese singularísimo saber hacer que fue el invento freudiano. El filósofo que acceda a recostarse en el diván se tratará a sí mismo de un modo que no es simétrico al de su profesión, y para formalizar eso que es un hecho de discurso, Lacan recurrió a la antifilosofía como un operador de distinción que no puede garantizar de antemano su sentido -ningún sentido- más 
allá del afán retórico-formativo de su promulgación. No podría ser de otro modo en el discurso psicoanalítico, pues

[...] lo que quiere producir no es ningún saber, sino un significante sin sentido reducido a letra. Su finalidad es epistémicamente débil, pero éticamente fuerte [...]. Es epistémicamente débil porque no busca la articulación del aparato simbólico, sino su desarticulación, y éticamente fuerte pues su orientación está dada por el acto analítico que consiste en gran medida en esa desarticulación entre el S1 y el saber, para proporcionar al sujeto un punto de apoyo nuevo, diferente del ideal, para su acto (Márquez, 2011).

A la luz de lo anterior, el tratamiento que ha recibido este término por parte de Badiou es tan sólo una muestra de que la inconmensurable distancia discursiva entre el psicoanálisis y la enseñanza universitaria no eximió a Lacan -ni a nosotros- de la difícil tarea de circunscribir el campo psicoanalítico en el seno de otros que lo someten constantemente a la demanda de articulación del sentido:

[a estas reglas] [...] tengo que abrirles paso, las que pretenden al menos dar las condiciones de un discurso propiamente analítico, estando éste por supuesto sometido al hecho de que de todas formas [...] que acá yo lo enuncié desde lo alto de una tribuna conlleva en efecto ese riesgo de error, ese elemento de refracción que hace que por algún lado caiga bajo el golpe del discurso universitario. Hay acá algo que se destaca como una especie de situación inestable de base. [...] Les aseguro que cada vez que vengo a hablar acá, no se trata para mi ciertamente de venir a decir lo que sea, [...] en ese aspecto no tengo que representar ningún rol, en el sentido de que la función del que enseña es del orden del rol, del lugar a sostener e incuestionablemente de un cierto lugar de prestigio; no es esto lo que me demando, sino más bien algo que es como un ordenamiento que me impongo la obligación de someter a esta prueba [...], rendir cuentas de lo que es el trayecto de mis acciones ante aquello que hay 'del psicoanalista', una posición que es la mía" (Lacan, 2008b, p. 44). 
No puede ser entonces sino un equívoco fundamental el que conduce a Badiou a atribuirle a Lacan una tesis secreta y sistemáticamente amenazante contra la filosofía. Si hacemos valer verdaderamente la cercanía lacaniana a la sofística, no tenemos razones para pensar que su propio decir no estaría sometido a sus planteamientos. Lo ha dicho Cassin (2013): "el sofista sabe que un contratorpedero es primeramente, y ante todo, un torpedero" (p. 61) y la cita precedente es muestra de la preocupación lacaniana porque su decir no sea investido con el poder de hacer advenir nuevos saberes integrales. Si lo que introduce el discurso analítico es precisamente una lógica distinta de esa que pretende llegar al núcleo último del sentido, no resulta verosímil entender su recurso a la antifilosofía como la formulación de un juicio afirmativo o negativo sobre la filosofía, sino en todo caso como una mención tautológica, referida al discurso mismo. Regnault (citado en Johnston, 2010) tiene razón en que la misión clave de la antifilosofía lacaniana se define justamente por no tratar de hacerse pasar por una visión de mundo suplente.

“¿Cómo quitarles de la cabeza el uso filosófico de mis términos, es decir, su uso soez?" (Lacan, 1988). Esa es, pues, la pregunta que reformulamos ante la propuesta filosófica badiousiana que, no obstante, quiso mantenerse fiel al maestro. En su momento hizo falta un manifiesto dadaísta para hacer tambalear esas certidumbres filosóficas que desdibujaban los linderos del discurso psicoanalítico. Y allí surgió la segunda y última mención del término por parte de Lacan:

El señor A, filósofo, que surgió quién sabe de dónde el sábado pasado y me dio la mano, hizo que me volviese a surgir un título de Tristán Tzara. [...] El señor A no me enternece, pues me hizo acordar del título: El señor Aa, el antifilósofo. Eso, eso me pasmó. En cambio, cuando le pasé a Tzara, que vivía en el mismo edificio que yo, La instancia de la letra, no le dio ni frío ni calor. Y yo que creía decir algo capaz de interesarlo. [...] El único delirio de Tzara era con Villon. Así y todo, él desconfiaba de este delirio. Yo no precisaba para nada que deliraran conmigo. Ya hacían eso unos cuantos. Y eso duró todavía. [...] Este señor Aa es antifilósofo. Es mi caso. Yo me sublevo, por decirlo así, contra la filosofía (Lacan, 1980). 
El texto de Tzara es todo menos fortuito en ese escenario donde Lacan recibe de los filósofos una admiración de la que no se siente cómplice ni conveniente objeto. Un exceso en torno a su persona anticipó en la ovación del filósofo; un exceso al que no sin cierto impudor denominó delirio. Y es que varios años antes que Badiou, fue el propio 'Señor $A^{\prime}$ quien se entregó a un análisis de la doctrina psicoanalítica desde el cual hizo surgir a Lacan como una espléndida promesa para la filosofía y para el marxismo (Bosteels, 2010, p. 194). No es nada menos que 'el delirio' de ese otro gran maestro que Badiou honra en el Panteón de su memoria, la causa de la identificación lacaniana con el antifilósofo.

La anécdota que protagoniza Luis Althusser por haber sido quien estrechó con entusiasmo la mano de Lacan evocándole el texto de Tzara que lo llevó a autoproclamarse como un antifilósofo, no debe ocluir el que quizá sea el movimiento más importante del manifiesto dadaísta con el que Lacan concluyó su enseñanza en la Escuela Freudiana de Paris: "Fíjense como lo digo de a poquito. Les doy tiempo para comprender. ¿Comprender qué? Yo no me jacto de hacer sentido. Tampoco de lo contrario. Pues lo real es lo que se opone a eso" (Lacan, 1980).

Lo real de la existencia que queda siempre por fuera de la palabra es lo que nos impide acompañar a Badiou en el bosquejo de la ficción bélica entre filosofía y psicoanálisis. Badiou encuentra en el psicoanálisis uno de los regímenes contemporáneos de condiciones que afectan y deciden el acto filosófico, uno de los dispositivos antifilosóficos desde los cuales la filosofía debe dejarse juzgar e instruir para levantar a partir de allí -como lo hiciera Platón en su diálogo con el sofista- las condiciones de posibilidad de la filosofía en nuestros días, pero

El psicoanálisis no tiene que rendir cuentas a la filosofía del error filosófico, como si la filosofía, a partir de ahí, debiera 'darse cuenta de él'. No puede haber nada semejante, puesto que en imaginárselo está precisamente el error filosófico mismo (Lacan, 2012, p. 223). 
Este pasaje es resolutorio. Siendo característico de la filosofía un cierto tipo de error, éste puede llegar a consistir en la suposición de que ella misma podría 'percatarse' de su error a partir del psicoanálisis, como si este albergara la promesa de un esclarecimiento de sentido. Y allí desemboca nuestro recorrido. Lacan no concibió el psicoanálisis como una suerte de filosofía alterna en la que pueda ser buscada la clave de una nueva crítica del juicio. Sostener esa idea no sólo es sostener la ilusión de que tal medida aguarda expectante en algún lugar, sino que implica suponerle demasiado al psicoanálisis. Si alguna objeción puede planteársele a Badiou es la que el propio psicoanálisis enuncia al afirmar que no hay medida -externa- para la ontología que los filósofos, de los que él forma parte, pretenden erigir; y que ni siquiera en la afirmación de que 'no hay medida' -que está allí dada como para ser tomada lisamente desde su vertiente universitaria- hay una nueva medida.

\section{Consideraciones finales}

Es el empuje por descifrar la clave del misterio y no el misterio mismo lo que puede llevarnos a caminos no analíticos. Más allá del concepto de lo real, lo que está en cuestión entre las posturas de nuestros autores es el modo mismo en que ambos se aproximan a aquello que es llamado 'concepto': se organiza el discurso en torno al nombre propio, o el vocablo se convierte en prisma que hace tambalear el sentido. El psicoanálisis, como apunta Cassin (2013), hace zumbar al significante apoyado en un discurso definido como sonido. ¿En qué autorizarnos entonces para considerar a Lacan un sofista inconsecuente? La prisa de quien quiere descifrar la clave del misterio no está prohibida, pero es precisamente ella la que no pertenece al discurso psicoanalítico.

¿Será entonces que aquel Lacan con el que polemiza Badiou no es Lacan de manera alguna? No parece ser más que un fantasma ese psicoanalista escéptico que de forma harto ligera levantó una filosofía antifilosófica sobre restos inconfesados de sofística. Ahora bien, quien ha llegado hasta acá no sólo verá que esa paradójica filosofía psicoanalítica jamás existió, sino que precisamente por ello, este asunto no se resuelve al compás de la theoria. El real que queda fuera de esta disertación -es lo que- la revela como puro discurso, mostrando en el acto que lo que verdaderamente importa 
de la antifilosofía para Lacan -así como de este texto para nosotros- se halla justo allí donde la contestación filosófica no alcanza. ¿Y es que acaso hemos hecho otra cosa que decir? Débil retórica anhelante de la poesía que requiere para iluminar un cambio de posición por el que, sabemos, el sentido no cesará de suspirar...

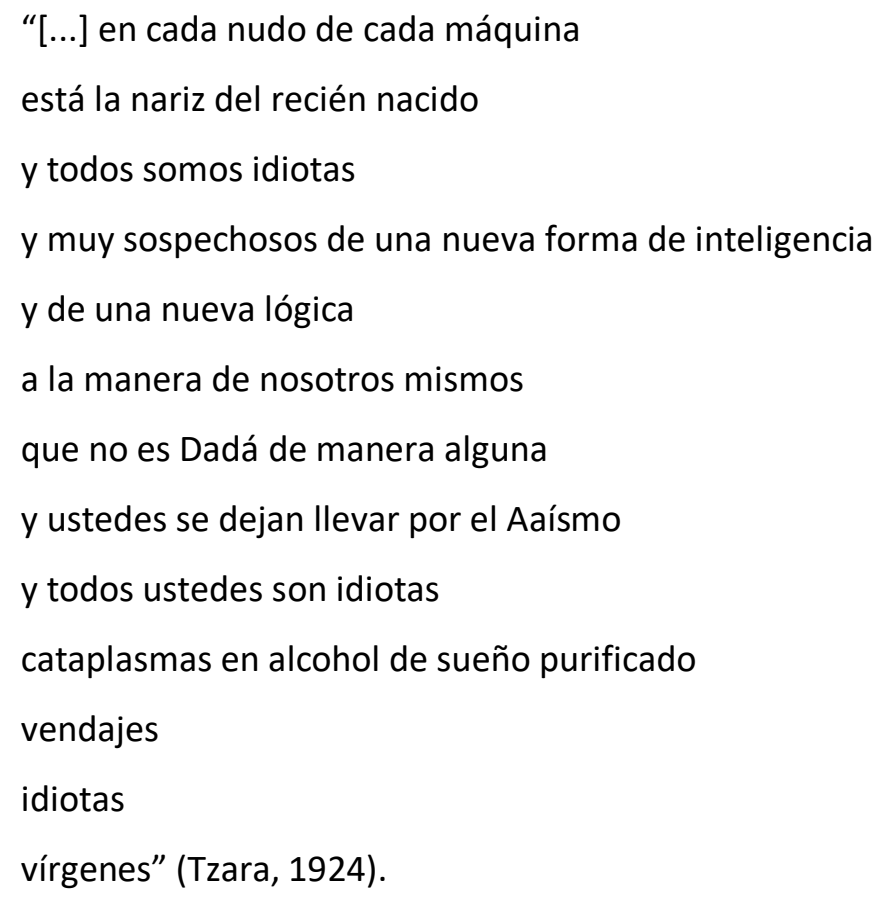

\section{Referencias:}

Badiou, A. (1990). Manifiesto por la filosofía. Buenos Aires: Nueva Visión.

Badiou, A. (2002). Condiciones. Buenos Aires: Siglo XXI Editores.

Badiou, A. (2003a). El ser y el acontecimiento. Buenos Aires: Manantial.

Badiou, A. (2003b) Pequeño panteón portátil. Buenos Aires: Manantial.

Badiou, A. (2006). Conferencias en Brasil: ética, política, globalización. Buenos Aires: Del Cifrado.

Badiou, A. (2008). Lógicas de los mundos. El ser y el acontecimiento, 2. Buenos Aires: Manantial.

Badiou, A. "Lacan y Platón: ¿es el matema una idea?". En Biblioteca del Colegio Internacional de Filosofía (2011). Lacan con los filósofos. Buenos Aires: Siglo XXI Editores.

Badiou, A. (2013). Filosofía y psicoanálisis. Buenos Aires: La Marca Editora. 
Balmès, F. (2002). Lo que Lacan dice del ser (1953-1960). Buenos Aires: Amorrortu.

Barrio, J. (Trad.). (1980). Protágoras y Gorgias. Fragmentos y testimonios. Buenos Aires: Ediciones Orbis.

Bassols, M. (2017). Acerca de la formación del analista, Bitácora lacaniana, 6: 39-49.

Bell, L. (2011). Articulations of the Real: from Lacan to Badiou, Paragrapgh, 34 (1): 105-120.

Biblioteca del Colegio Internacional de Filosofía (2011). Lacan con los filósofos. Buenos Aires: Siglo XXI Editores.

Bosteels, B. (2010). La teoría del sujeto de Alain Badiou: el reinicio del materialismo dialéctico. En S. Žižek (Ed.), Lacan. Los interlocutores mudos (p. 153-222), Madrid: Ediciones Akal.

Bosteels, B. (2008). Radical antiphilosophy, Filozofski Vestnik, 24 (2): 155-187.

Cassin, B. (2013). Jacques el sofista: Lacan, logos y psicoanálisis. Buenos Aires: Manantial.

Celedón, G. (2010). Badiou y Derrida en los bordes del acontecimiento, Revista Observaciones Filosóficas, 11: 1-13.

Cosentino, M. (2016). La antifilosofía de Jacques Lacan, Revista universitaria de psicoanálisis, 16: 123-132.

Dechen, C. (2013). Filosofía y ontología en el pensamiento de Alain Badiou, Scientia Helmantica, 1: 41-64.

Farrán, R. (2009). Subversión del sujeto: Althusser, Lacan, Badiou, Nómadas, 24 (4): 1-9.

Hallward, P. (2003). Badiou: a subject to truth. Minneapoli-London: University of Minnesota Press.

Johnston, A. (2010). This philosophy which is not one: Jean-Claude Milner, Alain Badiou and Lacanian Antophilosophy, Journal of the Jan van Eyck Circle for Lacanian Ideology Critique, 3: 137-158.

Lacan, J. (2008a). El seminario de Jacques Lacan, libro 11: Los cuatro conceptos fundamentales del psicoanálisis. Buenos Aires: Paidós.

Lacan, J. (2008b). El seminario de Jacques Lacan, libro 17: El reverso del psicoanálisis. Buenos Aires: Paidós. 
Lacan, J. (2008c). El seminario de Jacques Lacan, libro 19: ... O peor. Buenos Aires: Paidós.

Lacan, J. (2008d). El seminario de Jacques Lacan, libro 20: Aún. Buenos Aires: Paidós.

Lacan, J. (1988). La tercera. En Intervenciones y textos 2. Buenos Aires: Manantial.

Lacan, J. (1980). El Señor A. Obtenido el 26 de marzo de 2018 de Asociación mundial de psicoanálisis:_http://www.wapol.org/es/las_escuelas/TemplateArticulo.asp?intTi poPagina=4\&intEdicion=1\&int ldiomaPublicacion=1\&intArticulo=160\&int ldiomaArticulo=1\&i ntPublicacion $=10$

Lacan, J. (2012). Otros escritos. Buenos Aires: Paidós.

Laclau, E. (2004). Ética del compromiso militante, Virtualia, 12: 1-13.

Lüders, T. (2010). El fundamento negativo de lo político en le obra de Laclau, Badiou y Žižek, Cuadernos de Hideas, 4 (4): 11-24.

Márquez, C. (2011). Investigar en psicoanálisis, Nudos 3/4: 32-41.

Miller, J.-A. (2011). El ser y el uno. Caracas: Nueva Escuela Lacaniana.

Roudinesco, É., y Plon, M. (2008) Diccionario de psicoanálisis. Buenos Aires: Paidós.

Tho, T. (2015), Antiphilosophy. En S. Corcoran (Ed.), The Badiou Dictionary (p. 11-16), Edinburgh: Edinburgh University Press.

Tzara, T. (1924). Siete manifiestos Dada. París: Jean Budry. 